\title{
Original Research Article Research on the development of aesthetic education in primary and middle schools
}

\author{
Lei Wang* \\ Jiangsu normal university, Xuzhou, Jiangsu 221006, China.
}

\begin{abstract}
In recent years, social and economic development has been tremendous, but the people's spiritual quality, especially the development of aesthetic ability has been very poor. The exploration of aesthetic education has become an important node of liberal education and Education. For All, for the law and characteristics of aesthetic education in education and the development of campus aesthetic education put forward higher requirements and we need to continue to explore the process of aesthetic education and expand the status of education and aesthetic education. From the angle of aesthetics and pedagogy, following the characteristics of aesthetic education, this paper studies the development of aesthetic education and campus aesthetic education, aiming at improving the teaching of aesthetic education. With a view to improving the personal development of students, as well as the spirit of the whole society.
\end{abstract}

Keywords: Aesthetic Education; Aesthetic Education Teachers; Professional Quality; Campus Aesthetic Education

Aesthetic education leads us to have a pair of eyes that are good at discovering the beauty around us. Aesthetic education has brought up the spirit, culture, morality and other aspects of the Chinese nation, and has continuously sent fresh blood to the nation, it has laid a solid foundation for the realization of the Chinese dream.

Copyright (C) 2020 Lei Wang

doi: 10.18282/1-e.v9i4.1659

This is an open-access article distributed under the terms of the Creative Commons Attribution Non-Commercial License (http://creativecommons.org/licenses/by-nc/4.0/), which permits unrestricted non-commercial use, distribution, and reproduction in any medium, provided the original work is properly cited.

\section{Reference}

[1] Han Mengmeng, Zhu Sai, Wu Xiaohong. Research on sports fatigue and nutritional recovery of Competitive Aerobics athletes [J]. Combat (Martial Arts Science), 2014,11 (02): 114-116.

[2] Gao Chengli. Correct understanding and application of Yoga [J]. Sports science and technology literature bulletin, 2013,21 (03): 94-95.

[3] Deng Jia. Research on sports fatigue and recovery theory in track and field training [J]. Sci tech information, 2011 (10): 220 221.

[4] Liu Jiangbo, Li Jing, Li Yang, Cheng Yiran. Analysis on the development of Competitive Aerobics under the new rules of Competitive Aerobics in fig2017-2020 cycle [J]. Scientific mass (Scientific Education), 2020 (03): 188.

[5] Sports Fatigue Diagnosis of Aerobics Athletes in Liaoning Province, 2004.

[6] Du Xiru, Zhang linting. Experimental study on the influence of yoga on College Students' physical fitness and mental health

(J). Journal of Capital Institute of physical education, 2005 (01): 100-101.

[7] PansareMS, KulkarniAN, PendseUB. EffectofyogictrainingonserumLDHlevels [J] . JournalofSportsMedicine\& Physi calFit-ness, 1989, 29(2):177-178.

[8] The Effectsof Participating Hatha Yogaon the Physical-Psychological Functional Recoveryof Female University Students.2017,56(5):157-171.

[9] Wang Lei, Yi Xingfeng. Application of yoga in recovery training of middle and long distance running [J]. Journal of Social Sciences of Jiamusi University, 2011,29 (05): 168-170.

[10] Ding Zhiyuan. Research on yoga for football sports fatigue recovery [J]. Science and technology prospect, 2016,26 (05): 278.

[11] Gao Jie. Experimental study on the effect of yoga on fatigue recovery of Latin dance [D]. Xi' an Institute of physical education, 2015.

[12]Zhang Hui. Experimental research on yoga in basketball players' fatigue recovery after intensive training [D]. Jilin Institute of physical education, 2017. 


\section{The definition of aesthetic}

1793, Johann Schiller, one of the most representative masters of German classical literature, first put forward a more systematic and comprehensive theory of aesthetic education, which profoundly expounded the significance of aesthetic education. This book, known as "The manifesto of the first step of aesthetic education", provides a solid theoretical basis for the aesthetic education theory in China at the beginning of the 20th century ${ }^{[1]}$. There is education for health, cognition, morality, and education for aesthetic ability and virtue. This is the education of all-round moral, intellectual, physical, and aesthetic development and this is the education of all-round moral, intellectual, physical, and aesthetic development, through perceptual education to guide the sensitivity of perception, emotional diversity, the richness of imagination, to achieve a seamless connection between perceptual and rational. China's main advocate of aesthetic education is Cai Yuanpei, who first proposed "aesthetic education instead of religion" aesthetic educator, is the first advocate of aesthetic education in China. His "five-education" is famous in the world: military nationals, civic ethics, strength, world outlook and aesthetic. After more than 2000 years of reform, aesthetic education is not only education or art education, but to cultivate students' ability to appreciate and create beauty.

\section{The necessity of the construction of aesthetic education}

2015, the policy of "suggestions on strengthening and improving aesthetic education in schools in an all-round way" clearly put forward the important role of aesthetic education as a way to promote students' artistic attainment and cultivate the liberal education of all-round development ${ }^{[2]}$. Aesthetic Education is the forerunner of aesthetic education. With the improvement of material life, aesthetic education, a professional term which can be seen and cannot be touched, has entered into the depth of people's life, and also has a richer and more attractive unique connotation from the performance to the concrete in-depth. In order to better find the beauty around us, we should put the aesthetic education into the emotional and rational crystallization. Therefore, in order to find beautiful things, then we must first learn aesthetic, aesthetic education. The broad sense of aesthetic education needs the narrow sense of aesthetic education as a support. A person's aesthetic ability is also broad-minded performance, each thing has a beautiful side, broad-minded people can always use the aesthetic ability to find the beauty of life, which is the beauty of the form of things, personality, artistic conception, and so on. The Aristotle once proposed that aesthetic education has the functions of "education", "purification" and "spiritual enjoyment", aesthetic education promotes our aesthetic ability, makes us better at finding beauty, while getting "spiritual enjoyment", "purifying" one's own spiritual realm, and finding deficiency, paving the way to higher "substantial aesthetic education". Aesthetic education promotes the all-round development of individuals, aesthetic education, which includes all aesthetic activities and the mood of appreciating beauty, which is an imperceptible influence on the mind. In the narrow sense of educational environment, aesthetic education has been integrated into all disciplines, imperceptibly affecting the mind and body of the educated. The active development quality education, trains the student each interest and take the esthetic education as the foundation intellectual education, the moral education, the physical education, the labor ability comprehensive development.

\section{Discussion on the orientation of the development of aesthetic education}

With the development of aesthetic education on the stage of education, countless people who are concerned about the healthy development of aesthetic education began to discuss the development of aesthetic education. Aesthetic education is in the ascendant, we must devote ourselves to this "marathon" of aesthetic education, among which campus aesthetic education will be an important occasion for popularizing and promoting aesthetic education, based on the insight of society and the understanding of the national policy, we realize that the great role of campus aesthetic education should be brought into full play.

\subsection{Art education is a branch of aesthetic education.}

Aesthetic Education Without art education is incomplete education ${ }^{[3]}$. In contemporary aesthetic education, art curriculum, as one of the effective ways to implement aesthetic education in schools, providing convenient and effective conditions for the development of students, which makes students gradually improve their ability to appreciate and create beauty, it can also find the beautiful things from the details of life, cultivate the insight of observation, building a bridge between human life and nature and society, and comprehend the power of nature and the charm of ancient and modern Chinese and foreign arts. To cultivate the cultivation of aesthetic education from an early age, permeating aesthetic education knowledge in all aspects of school teaching and all kinds of educational places, and at the same time to cultivate the moral character of etiquette, patriotism and handling affairs brought about by educational activities, as Cai Yuanpei said, "all the courses in school have nothing to do with aesthetic education." It can be seen that the importance of aesthetic education must be exploited at all times, on the basis of educating people, we should pay attention to the necessity of aesthetic education. In our long-term practice, we have experienced the fruits of high artistic aesthetic ability, which can not only improve our ability and purify our hearts, but also inspire patriotism and social responsibility, which is one of the effective ways for contemporary students to perfect their thoughts and patterns. Secondly, school aesthetic education should be combined with family life aesthetic education. In many ordinary Chinese families, the awareness of children's aesthetic education is seriously inadequate. School aesthetic education should be extended to the guidance process of family aesthetic education to provide ways and means. Starting from school aesthetic education, aesthetic education becomes a universal educational activity that integrates school, family and society.

\subsection{The specific development of aesthetic education on campus}

The campus is a place where various kinds of teaching activities, after-school activities, students and certain persons related to the school are provided for daily life, including middle schools and primary schools. Campus almost accompany the majority of people from childhood to youth, so the development of campus aesthetic education has a great impact on the development of 
life. Teachers on campus play an immeasurable role. Teaching and educating people is an indispensable duty of every teacher, but as a teacher, especially the teacher of aesthetic education, teaching and educating people is far from enough. According to the requirements of the curriculum standards, achieving the required content of the curriculum is the most basic responsibility, aesthetic education teachers also need to have aesthetic education related skills, professional subject knowledge and innovative thinking. While carrying out teaching activities, we also need to have certain ability, especially in the teaching of art skills, aesthetic ability and other communication skills, from all aspects of the students' aesthetic education. At the same time, we should use the educational mechanism of campus to deal with the problems encountered in the course of aesthetic education.

\section{Conclusion}

In this era of rapid development, the government policy, the implementation of aesthetic education in schools and the cooperation of the society can better cultivate innovative talents with all-round development of morality, intelligence, Physique, beauty and labor. With the increasing importance of aesthetic education, it is the most effective way to promote the all-round development of the pillars of society in the future, which could plays a key role in the construction of social and spiritual civilization.

\section{References}

[1] Friedrich Schiller, On the Aesthetic Education of Man, In a Series of Letters, trans. Reginald SNELL, NEW YORK: Frederic Ungar Publishing Co., Ltd. 1954.

[2] Li Qingju. A study of Cai Yuanpei's thought of "substituting aesthetic education for religion". Nanjing University of Science and Technology, 2012.

[3] Wang Guowei. On the purpose of education [m] Wang Guowei's complete works: Volume 14. HANGZHOU: Zhejiang Education Press, Guangzhou: Guangdong Education Press, 2009. 